Article

\title{
Silane Modified Diopside for Improved Interfacial Adhesion and Bioactivity of Composite Scaffolds
}

\author{
Cijun Shuai ${ }^{1,2,3,4}$, Chenying Shuai ${ }^{1}$, Pei Feng ${ }^{1,2}$, Youwen Yang ${ }^{1,4}$, Yong $\mathrm{Xu}{ }^{1}$, Tian Qin ${ }^{1}$,
} Sheng Yang ${ }^{5}$, Chengde Gao ${ }^{1,2, *}$ and Shuping Peng ${ }^{6,7, *}$

1 State Key Laboratory of High Performance Complex Manufacturing, Central South University, Changsha 410083, China; shuai@csu.edu.cn (Cijun S.); shuaichenying@csu.edu.cn (Chenying S.); fengpei@csu.edu.cn (P.F.); yangyouwen@csu.edu.cn (Y.Y.); xuyong2927@csu.edu.cn (Y.X.); qintian@csu.edu.cn (T.Q.)

2 The State Key Laboratory for Powder Metallurgy, Central South University, Changsha 410083, China

3 Key Laboratory of Organ Injury, Aging and Regenerative Medicine of Hunan Province, Changsha 410008, China

4 State Key Laboratory of Solidification Processing, Northwestern Polytechnical University, Xi'an 710072, China

5 Human Reproduction Center, Shenzhen Hospital of Hongkong University, Shenzhen 518053, China; tobyys2000@aliyun.com

6 The Key Laboratory of Carcinogenesis of the Chinese Ministry of Health, Xiangya Hospital, Central South University, Changsha 410008, China

7 The Key Laboratory of Carcinogenesis and Cancer Invasion of the Chinese Ministry of Education, Cancer Research Institute, Central South University, Changsha 410078, China

* Corresponding author: gaochengde@csu.edu.cn (C.G.); shuping@csu.edu.cn (S.P.); Tel.: +86-731-8880-8205 (C.G.); +86-731-8480-5412 (S.P.); Fax: +86-731-8480-5383 (C.G.); +86-731-8887-9044 (S.P.)

Academic Editor: Derek J. McPhee

Received: 14 February 2017; Accepted: 21 March 2017; Published: 23 March 2017

\begin{abstract}
Diopside (DIOP) was introduced into polyetheretherketone/polyglycolicacid (PEEK/PGA) scaffolds fabricated via selective laser sintering to improve bioactivity. The DIOP surface was then modified using a silane coupling agent, 3-glycidoxypropyltrimethoxysilane (KH570), to reinforce interfacial adhesion. The results showed that the tensile properties and thermal stability of the scaffolds were significantly enhanced. It could be explained that, on the one hand, the hydrophilic group of KH570 formed an organic covalent bond with the hydroxy group on DIOP surface. On the other hand, there existed relatively high compatibility between its hydrophobic group and the biopolymer matrix. Thus, the ameliorated interface interaction led to a homogeneous state of DIOP dispersion in the matrix. More importantly, an in vitro bioactivity study demonstrated that the scaffolds with KH570-modified DIOP (KDIOP) exhibited the capability of forming a layer of apatite. In addition, cell culture experiments revealed that they had good biocompatibility compared to the scaffolds without KDIOP. It indicated that the scaffolds with KDIOP possess potential application in tissue engineering.
\end{abstract}

Keywords: diopside; silane coupling agent; interface adhesion; bioactivity; scaffolds

\section{Introduction}

Polyetheretherketone (PEEK), a semi-crystalline thermoplastic biopolymer, possesses great potential as a bone-repair material due to its superior mechanical properties, excellent temperature resistance and good processability [1-5]. Polyglycolicacid (PGA), a bioresorbable polymer, has proven to have remarkable qualities of biocompatibility and degradability [6,7]. A composite 
of the two biopolymers could realize appreciable improvement in degradability and mechanical properties. Nevertheless, the encountered problem is that PEEK/PGA composite is deficient in bioactive function [8-10].

Diopside (DIOP, $\mathrm{CaMgSi}_{2} \mathrm{O}_{6}$ ), as a calcium magnesium silicate bioceramic, has attracted attention for its favorable bioactivity and biocompatibility [11,12]. Moreover, it can release $\mathrm{Ca}, \mathrm{Mg}$ and $\mathrm{Si}$ ions, which would enhance osteoblast proliferations and stimulate gene expressions [13-15]. Recently, some studies have been primarily devoted to enhancing the bioactivity of biopolymers by way of the introduction of DIOP. Hosseini et al. developed electrospun poly( $\varepsilon$-caprolactone)-diopside scaffolds, and concluded that introducing DIOP into the scaffolds resulted in encouraging improvements in bioactivity and cellular behavior [16]. Kumar et al. fabricated chitosan-diopside composite scaffolds by sol-gel method, and found that introducing DIOP into the scaffolds showed improved bioactivity and biocompatibility [17]. Liu et al. prepared diopside/poly(L-lactide) scaffolds via the solution-casting method, and discovered that the composite scaffolds could significantly enhance the bioactivity and the attachment and proliferation of $\mathrm{MC}_{3} \mathrm{~T}_{3}-\mathrm{E}_{1}$ cells [18]. Therefore, PEEK/PGA composite combined with DIOP might possess good bioactive and biocompatible properties.

However, such inorganic particles tend to aggregate within the matrix on account of their incompatibility with biopolymers $[19,20]$. The phase-separation phenomena caused by this aggregation could induce interfacial adhesion failures, and thereby lead to the deterioration of the composite's mechanical properties $[21,22]$. Thus, the surface modification of DIOP particles using organic molecules is necessary. According to the principle of interface coupling [23,24], the hydrophilic group of the silane coupling agent could link with the hydroxy group on the DIOP surface by an organic covalent bond, and its hydrophobic group has a relatively high compatibility with the biopolymer matrix. So, the interfacial interaction would be improved between DIOP and the PEEK/PGA matrix by the modification of the silane coupling agent.

In this study, DIOP was incorporated into PEEK/PGA to improve the scaffold bioactivity. The silane coupling agent 3-glycidoxypropyltrimethoxysilane (KH570) was adopted to enhance the interface compatibility between DIOP and the biopolymer matrix. The PEEK/PGA-KDIOP composite scaffolds were fabricated via selective laser sintering (SLS). The microstructures, mechanical and thermal properties of the scaffolds were investigated. Meanwhile, the effects of KDIOP on bioactivity, degradation, and cellular response were also evaluated by simulated body fluid (SBF) immersion, phosphate buffer solution (PBS) soaking, and human osteosarcoma (MG-63) cells culture.

\section{Results and Discussion}

\subsection{Surface Modification of DIOP}

Phase separations are the greatest weakness in organic/inorganic composites $[25,26]$. The surface modification of inorganic particles was an effective approach to improving interfacial compatibility between the biopolymer and the inorganic phase [27]. A wide peak at about $3448 \mathrm{~cm}^{-1}$ was emerged in the spectra of the DIOP particles (Figure 1a). This hinted that there existed O-H stretching vibration on the DIOP surface, which could offer reaction sites for surface treatment through chemical bond. A strong Si-O-Si peak at around 467 and $1100 \mathrm{~cm}^{-1}$ and a weak Si-OH group at $963 \mathrm{~cm}^{-1}$ were also observed in the spectra. Moreover, it could be found that the new bands appeared at about $2856 \mathrm{~cm}^{-1}$ for the $-\mathrm{CH}_{2}$ group and $2938 \mathrm{~cm}^{-1}$ for the $-\mathrm{CH}_{3}$ group after DIOP was modified, which originated from the molecules of KH570. Furthermore, the new band observed at $1726 \mathrm{~cm}^{-1}$ was assigned to the $\mathrm{C}=\mathrm{O}$ stretch vibration of the carbonyl group, which was also derived from the molecule of KH570. The results implied that the KH570 was grafted successfully onto the surface of DIOP particles. 


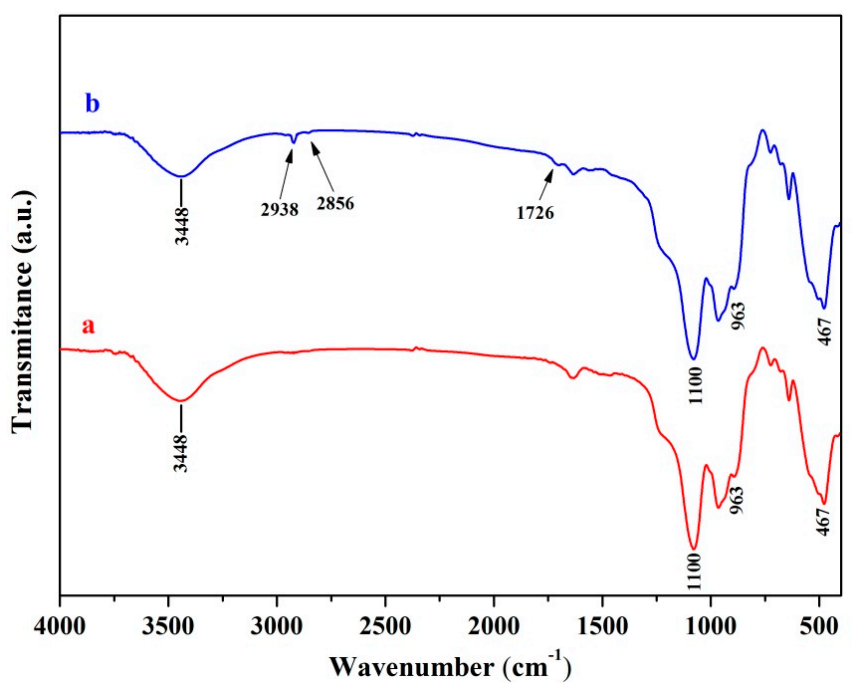

Figure 1. Fourier transform infrared (FTIR) spectra of (a) Diopside (DIOP) particles and (b) KH570-modified diopside (KDIOP) particles.

\subsection{Scaffold Fabrication}

The PEEK/PGA scaffolds with KDIOP were manufactured via SLS. The cylindrical scaffold had well-controlled pore size throughout, which was demonstrated from different perspectives (Figure 2). Its overall size was approximately $17 \mathrm{~mm} \times 8 \mathrm{~mm}$ (diameter $\times$ height), and each layer thickness was $1.6 \mathrm{~mm}$. The pore channel was fully interconnected and well-distributed throughout the whole scaffold, which was of significant importance for vascular ingrowth, nutrient transmission and cellular proliferation [28]. Kao et al. fabricated bio-inspired scaffolds and discovered that porous structure could improve cell adhesion and promote extracellular matrix (ECM) secretion [29]. Fantini et al. presented a porous biomimetic scaffold for bone tissue engineering, which could enhance cell proliferation and tissue regeneration [30].
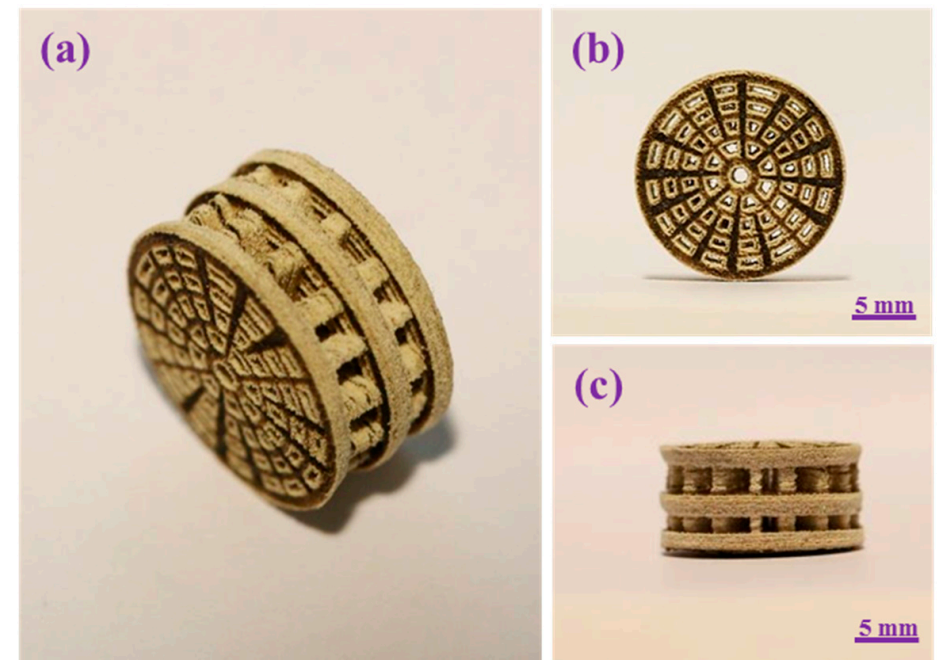

Figure 2. (a) Lateral view; (b) front view; and (c) isometric view of the PEEK/PGA-KDIOP composite scaffold.

\subsection{Microstructure and Mechanical Properties}

The tensile fracture surfaces morphology of the scaffolds was evaluated, and the composition of the PEEK/PGA-10\% KDIOP and PEEK/PGA-10\% DIOP scaffolds were detected by energy dispersive 
spectroscopy (EDS) in the yellow square areas (Figure 3). The morphology of PEEK/PGA scaffolds was flat and smooth. For PEEK/PGA-DIOP scaffolds, the agglomerated particles were clearly observed when the filler contents increased to $10 \mathrm{wt} \%$, and they were determined by EDS (Figure 3c). The appearance peaks of $\mathrm{Ca}, \mathrm{Mg}$ and $\mathrm{Si}$ verified that the agglomerated particles were DIOP. Moreover, the scaffolds with $15 \mathrm{wt} \%$ and $20 \mathrm{wt} \%$ DIOP yielded bulk agglomeration (Figure 3c,d). However, the KDIOP particles were evenly dispersed in the PEEK/PGA matrix when its contents did not exceed $10 \mathrm{wt} \%$. With the filler contents further increased to $15 \mathrm{wt} \%$ and $20 \mathrm{wt} \%$, there was a little agglomeration which existed in the biopolymer matrix. These results implied there was a good homogeneous state of dispersion in the scaffolds with KDIOP.
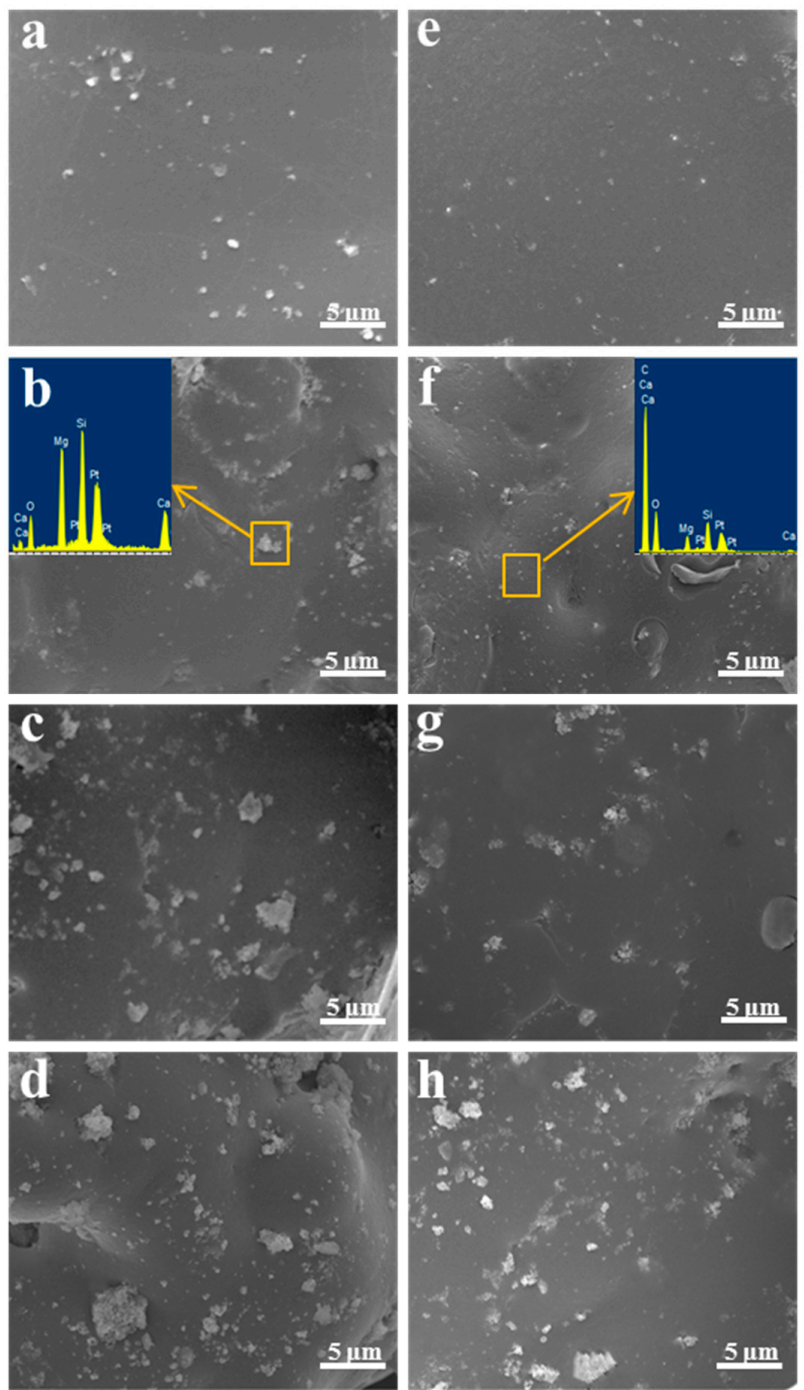

Figure 3. SEM micrographs of the tensile fracture surfaces of the scaffolds with (a-d) $5 \mathrm{wt} \%, 10 \mathrm{wt} \%$, 15 wt $\%$ and 20 wt \% DIOP; (e-h) 5 wt \%, 10 wt \%, 15 wt \% and $20 \mathrm{wt} \%$ KDIOP.

The mechanical characteristics of the PEEK/PGA-KDIOP scaffolds were assessed by tensile strength and tensile modulus (Figure 4). The PEEK/PGA scaffolds with KDIOP presented distinctly higher tensile strength than those of the scaffolds with the same quantities of DIOP. The tensile strength of the PEEK/PGA-KDIOP scaffolds almost remained stable as the KIOP content increased from $0 \mathrm{wt} \%$ to $10 \mathrm{wt} \%$. Nevertheless, their tensile strength decreased when the KDIOP contents were further increased. This might be due to the aggregation of the KDIOP particles in the biopolymer matrix (see Figure 3). On the contrary, the tensile strength of the PEEK/PGA-DIOP scaffolds decreased 
rapidly with increasing DIOP contents. These results can probably be attributed to the stronger interaction between the filler and matrix in the scaffolds with KDIOP than in the scaffolds without KDIOP. Furthermore, the tensile strength of the scaffolds with KDIOP (25-38 MPa) was higher than that of human cancellous bone (1-5 MPa) and close to that of cortical bone (50-151 MPa) [31,32]. The effects of the filling contents on the tensile modulus are shown in Figure $4 \mathrm{~b}$. The tensile modulus increased with increasing KDIOP contents. In addition, the KDIOP particles did not make remarkable differences on the modulus compared with DIOP particles. The reinforcement in the modulus was possibly because of the stiffness of fillers [33,34]. These results corresponded with the above SEM results, and the optimal filler content was $10 \mathrm{wt} \%$ in this study. Therefore, the scaffolds with $10 \mathrm{wt} \%$ KDIOP were selected for follow-up experiments.
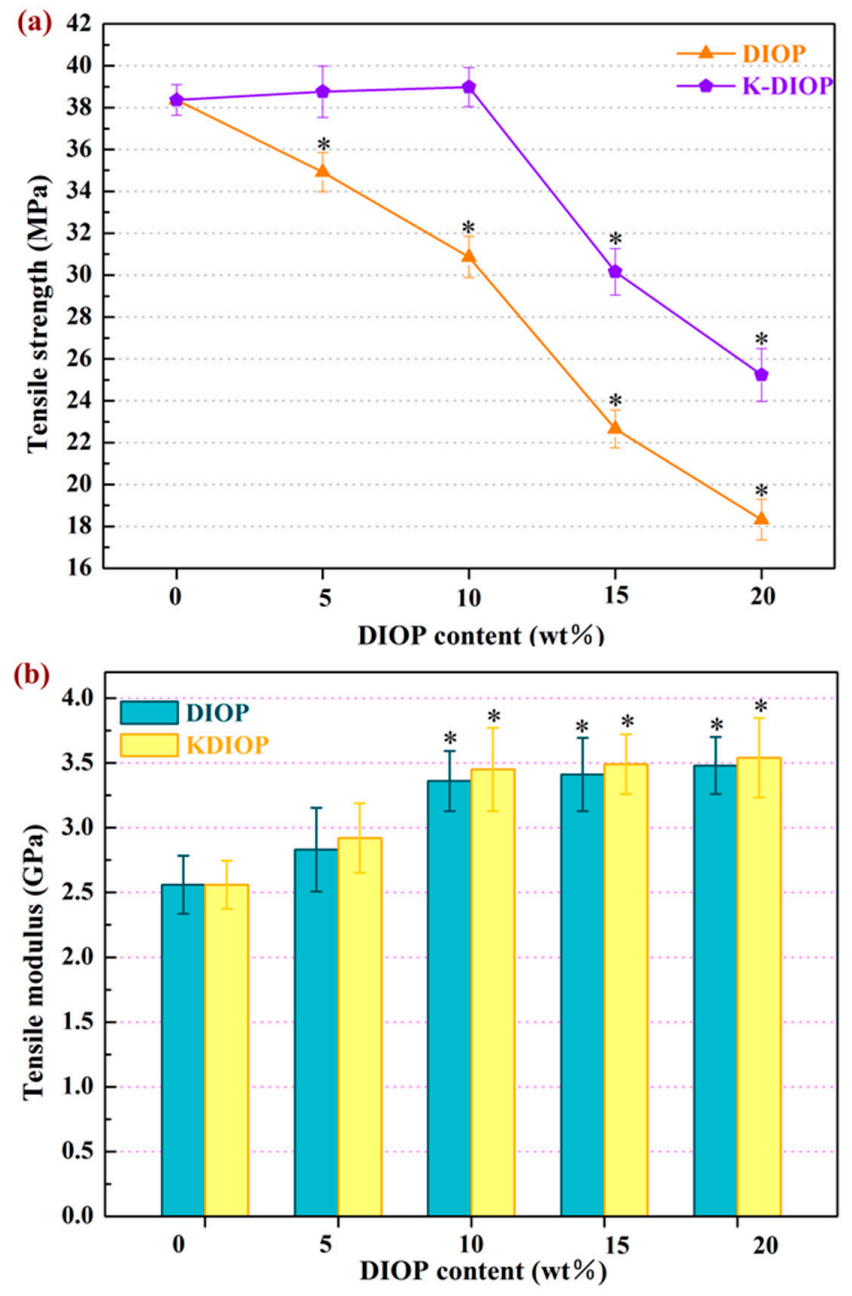

Figure 4. (a) Tensile strength; (b) tensile modulus of the polyetheretherketone/polyglycolicacid (PEEK/PGA)-DIOP and PEEK/PGA-KDIOP scaffolds. Significant difference between the composite scaffolds and the PEEK/PGA scaffold $\left({ }^{*} p<0.05\right)$.

\subsection{Thermal Properties}

The composite scaffolds were detected using differential scanning calorimetry (DSC) measurement. The DSC curve of PEEK/PGA scaffolds showed two distinct endothermic peaks at about $208^{\circ} \mathrm{C}$ and $323^{\circ} \mathrm{C}$, which coincided with endothermic peaks of PGA and PEEK [35,36]. Moreover, the melt temperatures of the PEEK/PGA-10\% DIOP and PEEK/PGA-10\% KDIOP scaffolds were higher than that of the PEEK/PGA scaffolds. The results were mainly because of the nucleation effects of DIOP particles, as they would hasten the development of a nucleus. Additionally, the dispersibility 
and compatibility of DIOP particles in the matrix were enhanced after modification, thus their melt temperature was certainly improved.

Thermogravimetric analysis (TGA) experiment was carried out to explore the influence of modified DIOP particles on the thermal stability of the PEEK/PGA scaffolds. The two-step degradation behaviors of the composite scaffolds were demonstrated (Figure 5). The first step was associated with the degradation of PGA, and the second step corresponded to the decomposition of PEEK. The composite scaffolds displayed higher degradation temperatures and less weight loss than the PEEK/PGA scaffolds. Furthermore, the noticeable degradation temperature increments of PEEK/PGA-10\% KDIOP were more than those of PEEK/PGA-10\% DIOP, which indicated that the PEEK/PGA scaffolds with KDIOP had higher thermal stability than the scaffolds with DIOP. This might be attributed to the strong interfacial interaction and good distribution of the KDIOP particles in the biopolymer matrix. As a consequence, the thermal motions of the polymer chains were restricted.
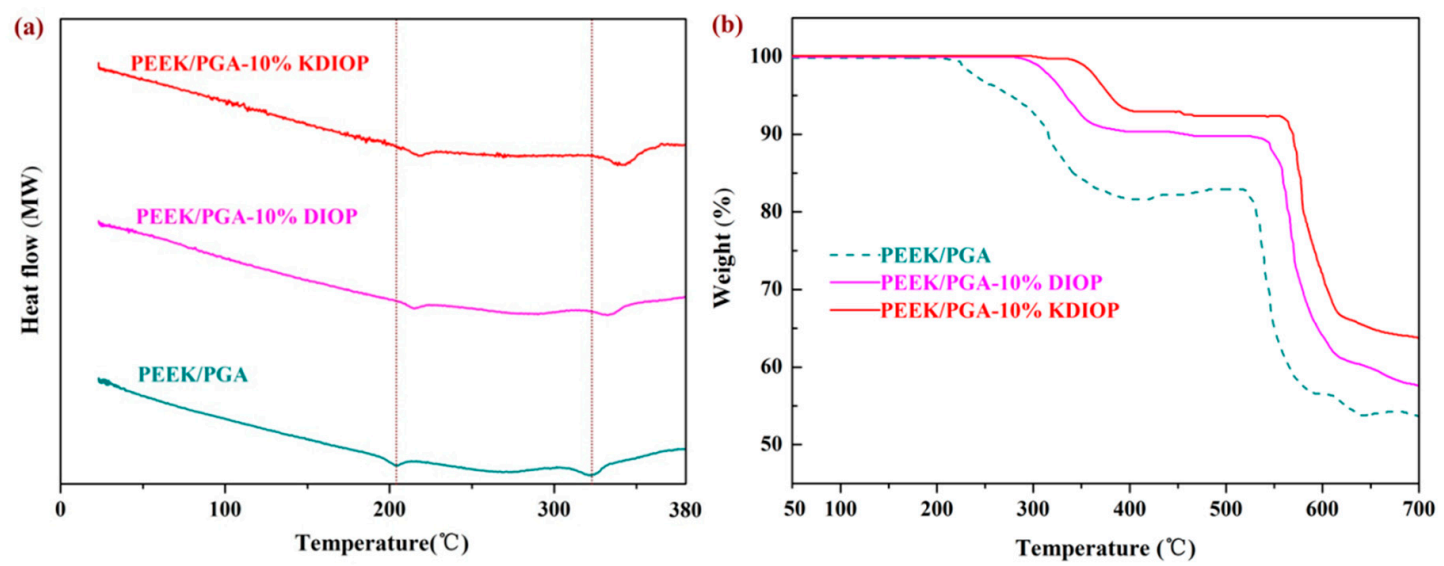

Figure 5. (a) Differential scanning calorimetry (DSC) and (b) Thermogravimetric analysis (TGA) plots of the scaffolds.

\subsection{In Vitro Bioactivity and Degradability}

The bioactivity of the scaffolds was assessed by immersing them into SBF. As seen, no sediments appeared on the PEEK/PGA scaffolds after immersion in SBF for 14 days, which verified that the composite of PEEK and PGA lacked bone-like apatite formability (Figure 6a). Conversely, a mass of cauliflower-like precipitates were formed on the surface of the PEEK/PGA-10\% DIOP and PEEK/PGA-10\% KDIOP scaffolds after immersion for 14 days.

The composition of the PEEK/PGA-10\% KDIOP scaffolds after immersion was assessed by Fourier transform infrared spectroscopy (Figure 7). The absorption peak at $983 \mathrm{~cm}^{-1}$ was assigned to the vibration modes of $\mathrm{PO}_{4}{ }^{3-}$ group in deposition. Moreover, the stretching vibration of the O-H group in hydroxyapatite was observed at $2847 \mathrm{~cm}^{-1}$. Additionally, new vibrational peaks corresponding to $\mathrm{CO}_{3}{ }^{2-}$ groups were also detected at $1468 \mathrm{~cm}^{-1}$. These results indicated the formation of bone-like apatite. Hence, it could be inferred that the scaffolds with KDIOP possessed apatite formability.

The degradation behaviors of the scaffolds were a crucial factor in bone regeneration [37]. The temporal $\mathrm{pH}$ changes were observed during the scaffolds' degradation (Figure 8a). For the PEEK/PGA scaffold, the $\mathrm{pH}$ declined remarkably from 7.4 to 6.5 during the 28 days of immersion. Meanwhile, for the PEEK/PGA-10\% DIOP and PEEK/PGA-10\% KDIOP scaffolds, a much slower decrease of $\mathrm{pH}$ was shown for the same soaking time. The results implied that the incorporation of KDIOP particles was able to alleviate the decrease of $\mathrm{pH}$ in a PBS solution. This might be explained by the dissolutions of alkaline ion from KDIOP particles, which could neutralize the acidifications of PBS owing to the acidic degradation product of PGA. The ameliorated acidity environment was beneficial to apatite formation [38]. In addition, it could also reduce the risk of inflammatory response in vivo [39]. 


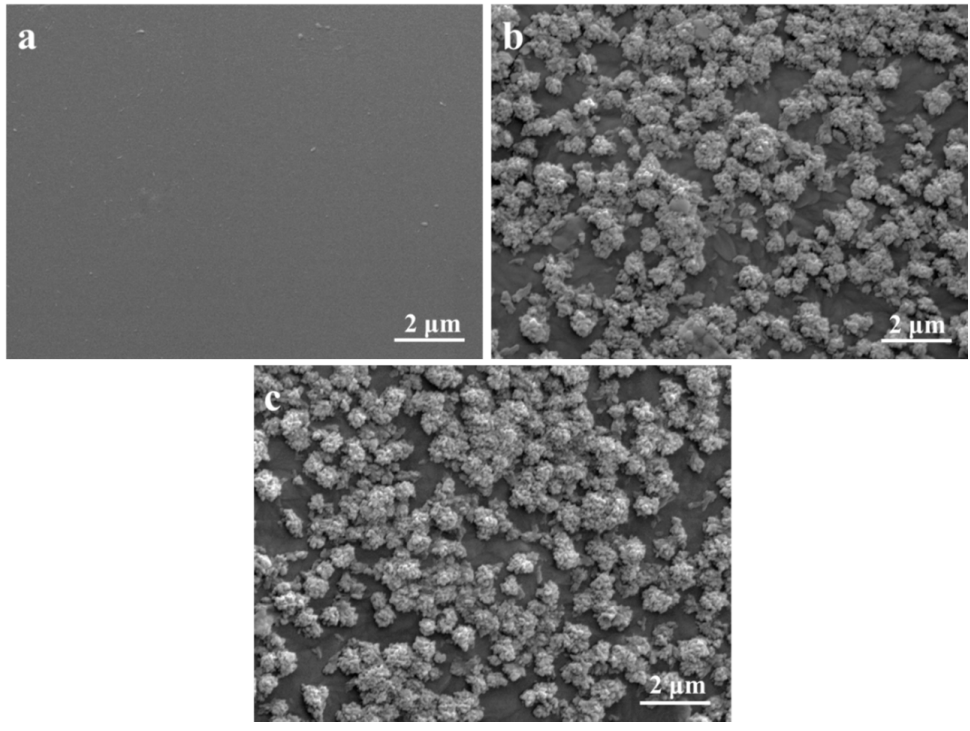

Figure 6. SEM micrographs of (a) PEEK/PGA; (b) PEEK/PGA-10\%DIOP; and (c) PEEK/PGA-10\% KDIOP scaffolds after immersion in simulated body fluid (SBF) for 14 days.

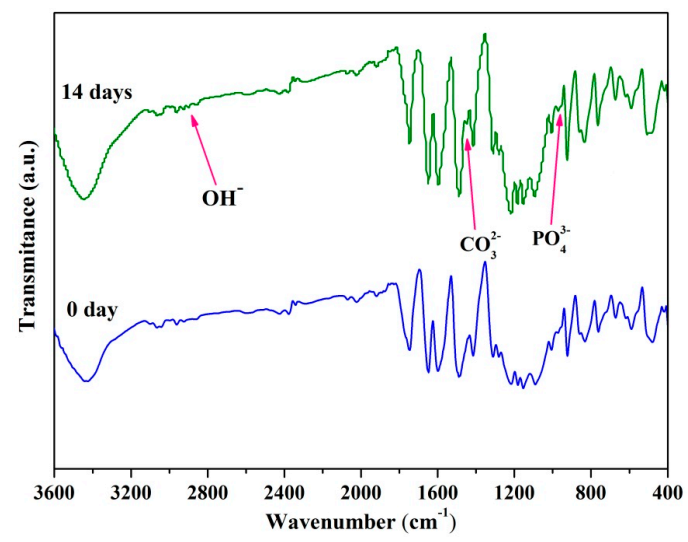

Figure 7. Fourier transform infrared spectrums of the scaffolds with $10 \%$ KDIOP after immersion in SBF.

The degradation was also evaluated using the weight loss method by the immersion for different periods in PBS (Figure 8b). It was found that weight losses of the scaffolds all gradually increased with the prolonged immersion time. Furthermore, the scaffolds with DIOP and KDIOP showed a lower weight loss than the PEEK/PGA scaffolds during 28 days of degradation (6.24\% and 6.11\%, respectively). This indicated that the introduction of KDIOP into the PEEK/PGA matrix could alleviate the likelihood of acid autocatalytic reaction, which is also in accordance with the results of the $\mathrm{pH}$ value.

\subsection{Biocompatibility Studies}

The cells proliferation on the scaffolds was investigated using MTT assay (Figure 9). Compared with a blank group, the increased optical density values of the cells showed that proliferation occurred on all scaffolds during the culture time. Moreover, after 7 days of incubation, the cell density of the PEEK/PGA-10\% KDIOP scaffolds increased approximately 136\%. Obviously, cell viability of MG-63 cells incubated on PEEK/PGA-10\% KDIOP was significantly higher than that on the PEEK/PGA scaffolds over different culture periods (1, 3 and 5 days). Therefore, the scaffolds with KDIOP could promote cell proliferation. This might be attributed to its function of cell recognition, which could sustain cell adhesion effectively. 
(a)
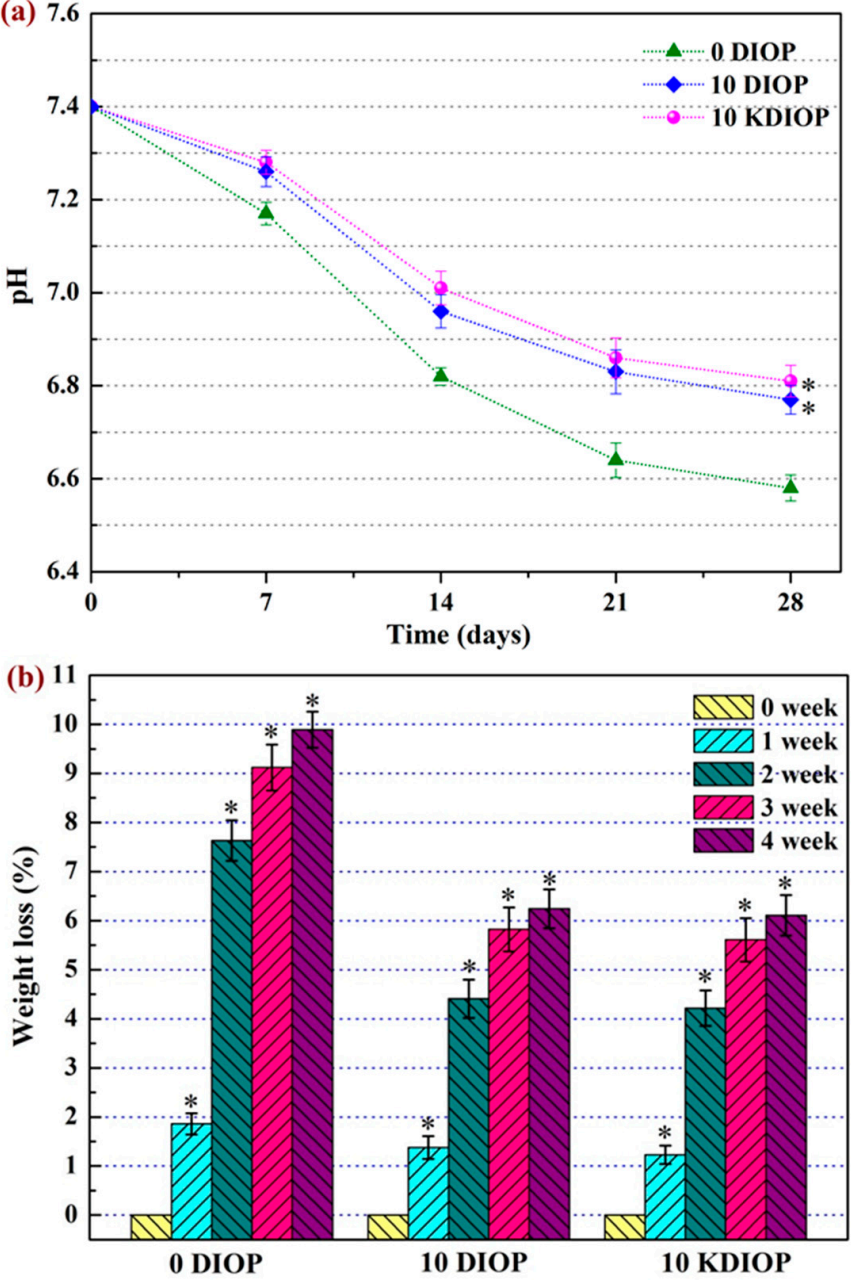

Figure 8. (a) $\mathrm{pH}$ value of PEEK/PGA, PEEK/PGA-10\% DIOP, and PEEK/PGA-10\% KDIOP scaffolds; (b) Weight loss of PEEK/PGA, PEEK/PGA-10\% DIOP, and PEEK/PGA-10\% KDIOP scaffolds after soaking in PBS. Significant difference between the composite scaffolds and PEEK/PGA scaffold $\left({ }^{*} p<0.05\right)$.

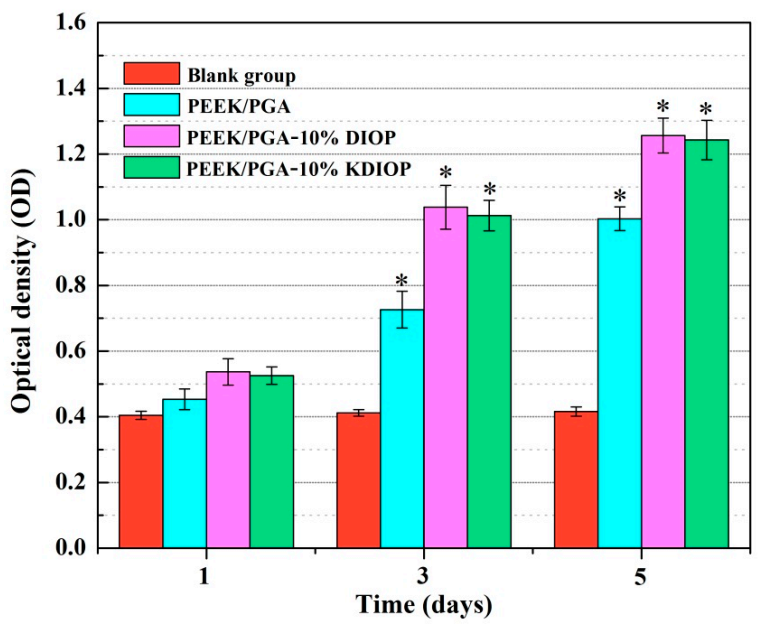

Figure 9. MTT assay for the scaffolds after culture periods of 1, 3 and 5 days. Significant difference between the scaffolds and the blank group $\left({ }^{*} p<0.05\right)$. 
Fluorescent photographs of MG-63 cells incubated for different periods are exhibited in Figure 10. All the live cells appeared light green. After 1 day of incubation, more cells attached on the PEEK/PGA-10\% KDIOP scaffolds than on the PEEK/PGA scaffolds. With the culture time prolonged, cells on the PEEK/PGA-10\% KDIOP scaffolds grew and spread with filopodia and lamellipodia, and they began to extending to nearby cells. As the culture time was prolonged to 7 days, the cells numbered much more than those on the PEEK/PGA scaffolds due to active intercellular interactions. The MTT and cell immunofluorescence studies showed that the scaffolds with KDIOP had a better biocompatibility. Moreover, some researchers have reported that the scaffolds modified by a silane coupling agent could support the growth of bone cells and tissues in vivo. Ma et al. found that the silane coupling agent KH560 modified HA/PEEK composites contributed to the growth of the surrounding bone tissues in vivo [40]. Wong et al. concluded that though bony in-growth was found in the Mg/PCL scaffolds modified with the silane coupling agent TMSPM [41].

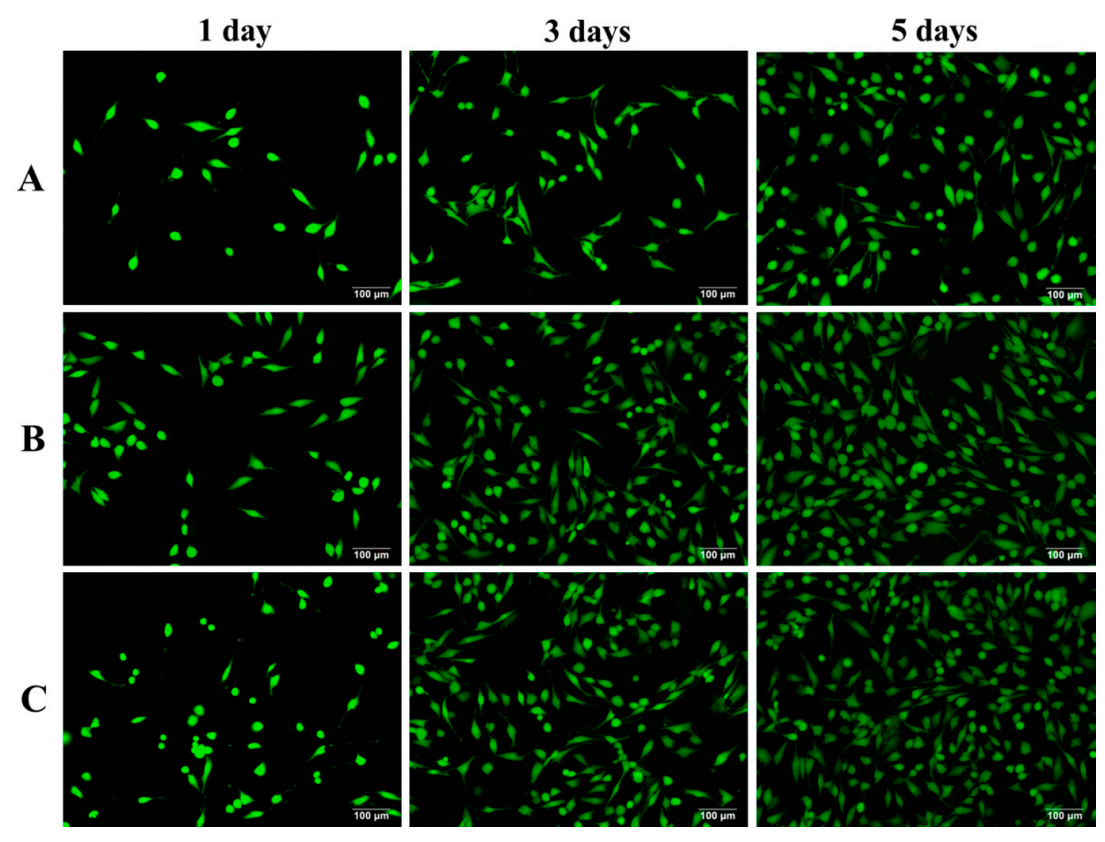

Figure 10. Fluorescence microscopy images of MG63 cells cultured on (A) PEEK/PGA; (B) PEEK/PGA-10\% DIOP and (C) PEEK/PGA-10\% KDIOP scaffolds.

\section{Materials and Methods}

\subsection{Materials}

PEEK, with average particle size ranging from 20 to $50 \mu \mathrm{m}$, was derived from Dongguan Guanhui Plastic Materials Co. Ltd. (Guangdong, China). PGA (particles size: $40 \mu \mathrm{m}, \mathrm{Mw}: 1,000,000 \mathrm{~g} / \mathrm{mol}$ ) was supplied by Shenzhen Polymtek Biomaterial Co. Ltd. (Shenzhen, China). DIOP (55 wt \% SiO $;$ 24 wt \% CaO; 18 wt \% MgO, particles size: $200 \mathrm{~nm}$ ) was obtained from Kunshan Chinese Technology New Materials (Kunshan, China). The silane coupling agent 3-glycidoxypropyltrimethoxysilane (KH570) was purchased from Nanjing Chuangshi Chemical Co. Ltd. (Nanjing, China).

\subsection{Surface Modification of DIOP}

KH570 with $0.5 \mathrm{wt} \%$ concentration was dissolved into $80 \mathrm{vol} \%$ anethanol-water mixture, then the $\mathrm{pH}$ of this solution was adjusted to $4.0 \mathrm{using}$ glacial acetic acid. The solutions were stirred and permitted to stand for hydrolysis for $1 \mathrm{~h}$. The DIOP particles were distributed in a hydroalocoholic solution at the ratio of $20 \%(w / v)$. Afterwards, the silane solutions were added to the DIOP slurries. The mixtures were stirred for $3 \mathrm{~h}$ with a magnetic stirrer at $50{ }^{\circ} \mathrm{C}$ under a nitrogen atmosphere. 
The surface modification of DIOP particles using KH570 was accomplished through desiccating the mixtures under a vacuum drying chamber at $100{ }^{\circ} \mathrm{C}$ for $4 \mathrm{~h}$. Subsequently, the surface-modified DIOP particles were washed thoroughly with ethanol. After centrifugation, the KH570-modified DIOP (KDIOP) was desiccated at $80^{\circ} \mathrm{C}$ for $12 \mathrm{~h}$ before use. The samples were recorded by Fourier transform infrared spectroscopy (DIOP) from $4000 \mathrm{~cm}^{-1}$ to $400 \mathrm{~cm}^{-1}$ with Nicolet 6700 spectrometer (Thermo Scientific Co., Madison, WI, USA). The mechanism of surface modification of DIOP particles was described in Figure 11.

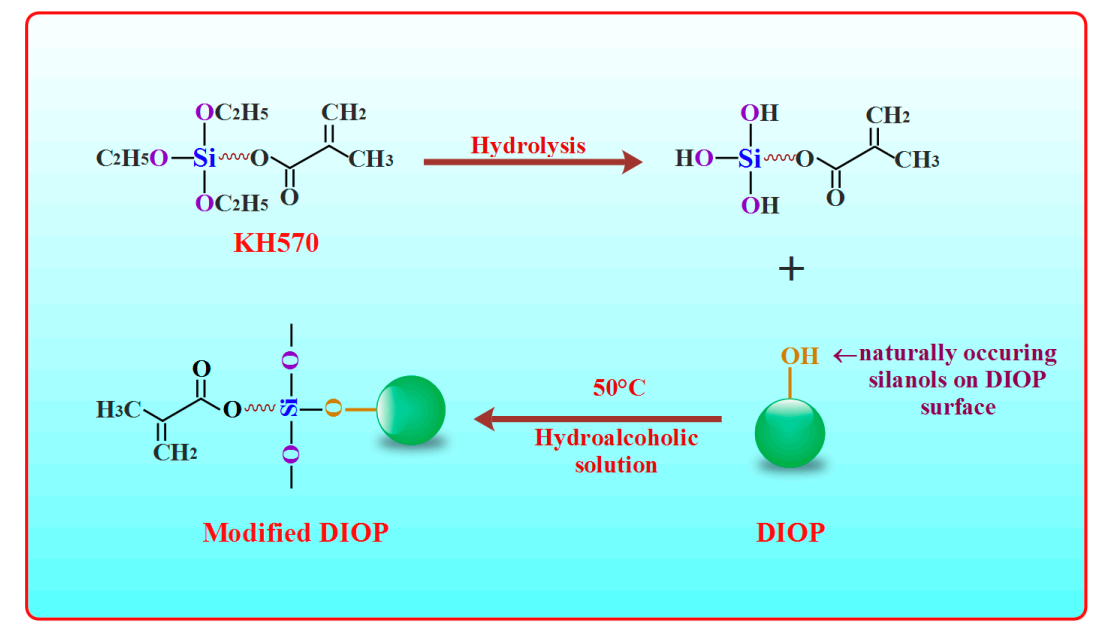

Figure 11. Schematic of silane reaction to produce the surface modified DIOP particles.

\subsection{Scaffolds Preparation}

PEEK powder and PGA powder were blended at a mass ratio of 8:2, and then ultrasonicated for $30 \mathrm{~min}$ in ethanol. Afterwards, they were mixed at $30 \mathrm{rpm}$ for $1 \mathrm{~h}$ with a variable frequency ball mill. Subsequently, the KDIOP particles were added into the PEEK/PGA solution in proportions of $5 \%, 10 \%$, and $15 \%$ of total weight, respectively. For comparison, the DIOP particles were added into the biopolymer solution in proportions of $5 \%, 10 \%$, and $15 \%$ of total weight, respectively, too. Next, the mixtures were sonicated and stirred for $30 \mathrm{~min}$ to homogeneously disperse the particles in the PEEK/PGA solutions. After that, they were exsiccated under a draught drying cabinet.

The prepared powder was used for fabricating porous scaffolds with selective laser sintering (SLS). The SLS system was equipped with a $100 \mathrm{~W} \mathrm{CO}_{2}$ laser, sintering platform, motion platform and a control system [42,43]. During the processes of sintering, the focus laser beam sintered the mixed powders on the selected area layer by layer to manufacture the scaffolds. All the preparation parameters maintained the following constants: laser spot diameter $0.8 \mathrm{~mm}$, laser power $2.5 \mathrm{~W}$, scan line interval $3 \mathrm{~mm}$, powder layer thickness $0.1-0.2 \mathrm{~mm}$ and scanning speed $400 \mathrm{~mm} / \mathrm{min}$.

\subsection{Characterization}

The morphologies and elemental constitution analysis of the PEEK/PGA-KDIOP and PEEK/PGA-DIOP composite scaffolds were detected using scanning electron microscopy (SEM, Hillsboro, OR, USA) equipped for energy dispersive spectroscopy (EDS, Hillsboro, OR, USA). The scaffold specimens were quenched into the liquid nitrogen, and then coated with gold for $200 \mathrm{~s}$ by a JFC-1600 sputter coater prior to SEM observation. Simultaneous thermogravimetric analysis/differential scanning calorimetry (TGA/DSC) system (STA-200 instruments, Nanjing Dazhan Institute of Electromechanical Technology, Nanjing, China) was employed to analyze the thermal behaviors of the composite scaffolds. DSC measured the heat flow linked with thermally active transitions. Samples (about $8 \mathrm{mg}$ ) were sealed into aluminum pans and then were heated from $25^{\circ} \mathrm{C}$ to $380^{\circ} \mathrm{C}$ under a nitrogen atmosphere at the heating rate of $10^{\circ} \mathrm{C} / \mathrm{min}$. TGA measured the rate and 
amount of weight changes in scaffolds. The tests were performed over an extensive range of $50{ }^{\circ} \mathrm{C}$ to $700{ }^{\circ} \mathrm{C}$ under an inert atmosphere at the heating rate of $10^{\circ} \mathrm{C} / \mathrm{min}$. The decomposition temperatures could be obtained from the plots. Tensile strength of the PEEK/PGA-KDIOP and PEEK/PGA-DIOP composite scaffolds was determined by an electron universal testing machine. The scaffold samples $\left(10 \times 10 \times 5 \mathrm{~mm}^{3}\right)$ were measured at ambient conditions, and a crosshead speed was set to $0.5 \mathrm{~mm} / \mathrm{min}$. The modulus was determined by the initial linear slopes of the stress-strain curve. Each data point was obtained from the average value over five replicate samples.

\subsection{Biomineralization and Degradation}

The bioactive studies were carried out using standard SBF solution, which was prepared according to the protocol proposed by Kokubo et al. [44]. Inorganic ion components of the solution resembled those of human blood plasma. All the composite scaffolds were immersed into SBF ( $\mathrm{pH}=7.4)$ for 14 days at $37^{\circ} \mathrm{C}$, and the SBF solution was refreshed every second day. After immersion, they were taken out, then gently purged with redistilled water and vacuum dried at $37^{\circ} \mathrm{C}$ overnight. The surface morphologies of scaffolds and chemical functional groups of the precipitated apatite layer were analyzed by SEM and FTIR spectroscopy, respectively.

The degradation of the PEEK/PGA-KDIOP and PEEK/PGA-DIOP scaffolds was assessed in PBS solution ( $\mathrm{pH}=7.4)$. Three specimens from each group were weighted $\left(W_{i}\right)$. Afterwards, they were placed into the solution and incubated at $37^{\circ} \mathrm{C}$ for various periods $(1,2,3$ and 4 weeks). The solution was weekly renewed with fresh PBS. At each predetermined time, the samples were fetched out, carefully rinsed with ethanol and thoroughly dried to achieve constant weight $\left(W_{f}\right)$. The weight loss percentage was identified as [45]:

$$
\text { weight loss }(\%)=\frac{W_{i}-W_{f}}{W_{i}} \times 100 \%
$$

Meanwhile, $\mathrm{pH}$ changes of the PBS solutions were detected with an electrolyte-type pH meter.

\subsection{Cell Culture}

MG-63 osteoblast-like cells were used in the cytocompatibility evaluation of the PEEK/PGA-KDIOP and PEEK/PGA-DIOP scaffolds. The MG-63 cells line was incubated in Dulbecco's modified Eagle's medium (DMEM), supplemented with $10 \%(v / v)$ fetal bovine serum (FBS) and $1 \%$ penicillin/streptomycin under the atmosphere of $5 \% \mathrm{CO}_{2}$ at $37{ }^{\circ} \mathrm{C}$. Prior to cell seeding, all the scaffolds were rinsed using 70\% ethanol, and then cleaned three times after being sterilizing under ultraviolet for $30 \mathrm{~min}$ [46]. Afterwards, the cells were seed on the composite scaffolds at the density of 20,000 cells / well and incubated in the 12-well plate for different periods (1, 4 and 7 days). The cultured medium were maintained under the humidified atmosphere at $37^{\circ} \mathrm{C}$, and renewed once every two days. After the indicated time, scaffolds were taken out, cleaned in PBS, and then the cells attached on the scaffolds were fixed with modified Karnovsky's fixative and dehydrated with ethyl alcohol solution.

Additionally, microculture tetrazolium test (MTT) assay was conducted to assess the cell proliferation on the scaffolds. At a preselected culture time, $20 \mu \mathrm{L}$ of MTT solution were added to cell culture plates and kept for $3 \mathrm{~h}$ at $37^{\circ} \mathrm{C}$. Subsequently, $200 \mathrm{~mL}$ dimethyl sulphoxide (DMSO) were taken into each plate to completely dissolve formazan crystals after discarding the supernatants. In the end, the absorbency was determined at $570 \mathrm{~nm}$ with a microplate reader. Moreover, the culture medium was used as the control group.

Cell viability of scaffolds was investigated by fluorescence techniques. After cell incubation, the scaffolds were fetched out and cleaned with PBS, immobilized using paraformaldehyde solution and then permeabilized with $0.5 \%$ Triton for $10 \mathrm{~min}$. Afterwards, the cells were purged using PBS and preincubated with FBS. Following this, cells were washed again and fostered into $2 \mu \mathrm{M}$ calcein AM 
and $4 \mu \mathrm{M}$ EthD- 1 for $20 \mathrm{~min}$. In the end, fluorescence figures were taken under a confocal fluorescence microscope (Leica Microsystem, Mannheim, Germany).

\subsection{Statistical Analysis}

The data for tensile tests, weight loss, $\mathrm{pH}$ value and MTT assay were analyzed using Origin 8.0 software. The results were presented as a mean \pm standard deviation $(n=6)$. In all analyses, statistical significance was assessed via Student's t-test $(p<0.05)$.

\section{Conclusions}

The DIOP particles were successfully modified using a silane coupling agent (KH570) and the PEEK/PGA scaffolds with the modified DIOP were developed via selective laser sintering. The modification of DIOP could decrease the particle agglomeration and increase the particle dispersion in the PEEK/PGA matrix. The tensile strength of the PEEK/PGA-KDIOP scaffolds was enhanced, indicating the good compatibility and dispersibility between the biopolymer matrix and KDIOP. Moreover, the thermal stability was also elevated. Furthermore, the introduction of KDIOP into the PEEK/PGA matrix could improve the bioactivity of the scaffolds, and facilitate cell attachment and proliferation. Thus, the PEEK/PGA scaffolds with KDIOP would be a potential candidate for bone repair.

Acknowledgments: This work was supported by the following funds: (1) The Natural Science Foundation of China (51575537, 81572577); (2) Overseas, Hong Kong \& Macao Scholars Collaborated Researching Fund of National Natural Science Foundation of China (81428018); (3) Hunan Provincial Natural Science Foundation of China (14JJ1006, 2016JJ1027); (4) The Project of Innovation-driven Plan of Central South University (2015CXS008, 2016CX023); (5) The Open-End Fund for the Valuable and Precision Instruments of Central South University; (6) The fund of the State Key Laboratory for Powder Metallurgy; (7) The Fundamental Research Funds for the Central Universities of Central South University.

Author Contributions: Chenying Shuai, Yong $\mathrm{Xu}$ and Pei Feng fabricated the scaffolds and carried out the mechanical testing under the supervision of Cijun Shuai, the microstructural characterization of the scaffolds under the supervision of Youwen Yang and Sheng Yang, Tian Qin performed the biological testing of the scaffolds under the supervision of Cijun Shuai, the biological characterization of the scaffolds under the supervision of Shuping Peng and Chengde Gao. All authors discussed the results and implications and approved the final manuscript.

Conflicts of Interest: The authors declare no conflict of interest.

\section{References}

1. Vaezi, M.; Black, C.; Gibbs, D.M.R.; Oreffo, R.O.C.; Yang, S. Characterization of new PEEK/HA composites with 3D HA network fabricated by extrusion freeforming. Molecules 2016, 21, 6. [CrossRef] [PubMed]

2. Wang, B.; Gan, K.; Liu, H.; Song, X.; Liu, X.; Niu, D.; Chen, T.; Liu, C. Preparation and mechanical properties of polyethereketone biocomposite for prosthodontics. J. Biomater. Tissue Eng. 2017, 7, 45-52. [CrossRef]

3. Liu, C.; Chan, K.; Shen, J.; Liao, C.; Yeung, K.; Tjong, S. Polyetheretherketone hybrid composites with bioactive nanohydroxyapatite and multiwalled carbon nanotube fillers. Polymers 2016, 8, 425.

4. Vaezi, M.; Yang, S. Extrusion-based additive manufacturing of PEEK for biomedical applications. Virtual Phys. Prototyp. 2015, 10, 123-135. [CrossRef]

5. Vaezi, M.; Yang, S. A novel bioactive PEEK/HA composite with controlled 3D interconnected HA network. Int. J. Bioprint. 2015, 1, 66-76. [CrossRef]

6. Dragojevic, S.; Ryu, J.S.; Raucher, D. Polymer-based prodrugs: Improving tumor targeting and the solubility of small molecule drugs in cancer therapy. Molecules 2015, 20, 21750. [CrossRef] [PubMed]

7. Sobczak, M.; Dębek, C.; Olędzka, E.; Kozłowski, R. Polymeric systems of antimicrobial peptides-strategies and potential applications. Molecules 2013, 18, 14122. [CrossRef] [PubMed]

8. Aghdam, R.M.; Najarian, S.; Shakhesi, S.; Khanlari, S.; Shaabani, K.; Sharifi, S. Investigating the effect of pga on physical and mechanical properties of electrospun pcl/pga blend nanofibers. J. Appl. Polym. Sci. 2012, 124, 123-131. [CrossRef] 
9. Deng, Y.; Liu, X.; Xu, A.; Wang, L.; Luo, Z.; Zheng, Y.; Deng, F.; Wei, J.; Tang, Z.; Wei, S. Effect of surface roughness on osteogenesis in vitro and osseointegration in vivo of carbon fiber-reinforced polyetheretherketone-nanohydroxyapatite composite. Int. J. Nanomed. 2015, 10, 1425.

10. Wang, L.; He, S.; Wu, X.; Liang, S.; Mu, Z.; Wei, J.; Deng, F.; Deng, Y.; Wei, S. Polyetheretherketone/ nano-fluorohydroxyapatite composite with antimicrobial activity and osseointegration properties. Biomaterials 2014, 35, 6758-6775. [CrossRef] [PubMed]

11. Shuai, C.; Liu, T.; Gao, C.; Feng, P.; Xiao, T.; Yu, K.; Peng, S. Mechanical and structural characterization of diopside scaffolds reinforced with graphene. J. Alloy Compd. 2016, 655, 86-92.

12. Fiocco, L.; Elsayed, H.; Ferroni, L.; Gardin, C.; Zavan, B.; Bernardo, E. Bioactive wollastonite-diopside foams from preceramic polymers and reactive oxide fillers. Materials 2015, 8, 2480-2494. [CrossRef]

13. Wu, C.; Ramaswamy, Y.; Zreiqat, H. Porous diopside (CaMgSi(2)O(6)) scaffold: A promising bioactive material for bone tissue engineering. Acta Biomater. 2010, 6, 2237-2245. [CrossRef] [PubMed]

14. Sun, J.; Li, J.; Liu, X.; Wei, L.; Wang, G.; Meng, F. Proliferation and gene expression of osteoblasts cultured in dmem containing the ionic products of dicalcium silicate coating. Biomed. Pharmacother. 2009, 63, 650-657. [CrossRef] [PubMed]

15. Kouhi, M.; Shamanian, M.; Fathi, M.; Samadikuchaksaraei, A.; Mehdipour, A. Synthesis, characterization, in vitro bioactivity and biocompatibility evaluation of hydroxyapatite/bredigite $\left(\mathrm{Ca}_{7} \mathrm{MgSi}_{4} \mathrm{O}_{16}\right)$ composite nanoparticles. JOM 2016, 68, 1061-1070. [CrossRef]

16. Hosseini, Y.; Emadi, R.; Kharaziha, M.; Doostmohammadi, A. Reinforcement of electrospun poly( $\varepsilon$-caprolactone) scaffold using diopside nanopowder to promote biological and physical properties. J. Appl. Polym. Sci. 2016, 134, 6. [CrossRef]

17. Kumar, J.P.; Lakshmi, L.; Jyothsna, V.; Balaji, D.R.P.; Saravanan, S.; Moorthi, A.; Selvamurugan, N. Synthesis and characterization of diopside particles and their suitability along with chitosan matrix for bone tissue engineering in vitro and in vivo. J. Biomed. Nanotechnol. 2014, 10, 970-981. [CrossRef] [PubMed]

18. Liu, Z.; Ji, J.; Tang, S.; Qian, J.; Yan, Y.; Yu, B.; Su, J.; Wei, J. Biocompatibility, degradability, bioactivity and osteogenesis of mesoporous/macroporous scaffolds of mesoporous diopside/poly(L-lactide) composite. J. R. Soc. Interface 2015, 12, 20150507. [CrossRef] [PubMed]

19. Boccaccini, A.R.; Erol, M.; Stark, W.J.; Mohn, D.; Hong, Z.; Mano, J.F. Polymer/bioactive glass nanocomposites for biomedical applications: A review. Compos. Sci. Technol. 2010, 70, 1764-1776. [CrossRef]

20. Bunk, J.K.G.; Drechsler, A.; Rauch, S.; Uhlmann, P.; Stamm, M.; Rennekamp, R. The distribution of hydrophobized inorganic nanoparticles in thermoresponsive polymer nanocomposite films investigated by scanning probe and electron microscopy. Eur. Polym. J. 2013, 49, 1994. [CrossRef]

21. Kongsinlark, A.; Rempel, G.L.; Prasassarakich, P. Synthesis of monodispersed polyisoprene-silica nanoparticles via differential microemulsion polymerization and mechanical properties of polyisoprene nanocomposite. Chem. Eng. J. Chem. Eng. J. 2012, 193, 215-226. [CrossRef]

22. Hristov, V.; Krumova, M.; Michler, G. The influence of excess coupling agent on the microdeformation processes and mechanical properties of poly(propylene)/wood-flour composites. Macromol. Mater. Eng. 2010, 291, 677-683. [CrossRef]

23. Zheng, Y.T.; Cao, D.R.; Wang, D.S.; Chen, J.J. Study on the interface modification of bagasse fibre and the mechanical properties of its composite with PVC. Compos. Part A Appl. Sci. Manuf. 2007, 38, 20-25. [CrossRef]

24. Abdelwahab, N.A.; Helaly, F.M. Chemically modified sugarcane bagasse as an improving agent for the properties of styrene-butadiene rubber. J. Appl. Polym. Sci. 2010, 113, 3470-3476.

25. Kim, S.; Wang, X.; Ando, S.; Wang, X. Hybrid ternary composites of hyperbranched and linear polyimides with $\mathrm{SiO}_{2}$ : A research for low dielectric constant and optimized properties. RSC Adv. 2014, 4, 42737-42746. [CrossRef]

26. Han, Q.; Pei, Y.; Zhong, Y.; Zhang, K.; Tang, L.; Wu, L. Fabrication and properties of chemically bonded polysilsesquioxane-polyacrylate/silica hybrid latex films with high silicon content. Polym. Compos. 2015, 36, 389-396. [CrossRef]

27. Pu, Z.; Tang, H.; Huang, X.; Yang, J.; Zhan, Y.; Zhao, R.; Liu, X. Effect of surface functionalization of $\mathrm{SiO}_{2}$ particles on the interfacial and mechanical properties of pen composite films. Colloids Surf. A 2012, 415, 125-133. [CrossRef]

28. Feng, P.; Niu, M.; Gao, C.; Peng, S.; Shuai, C. A novel two-step sintering for nano-hydroxyapatite scaffolds for bone tissue engineering. Sci. Rep. 2013, 4, 5599. [CrossRef] [PubMed] 
29. Kao, C.T.; Lin, C.C.; Chen, Y.W.; Yeh, C.H.; Fang, H.Y.; Shie, M.Y. Poly(dopamine) coating of 3D printed poly(lactic acid) scaffolds for bone tissue engineering. Mater. Sci. Eng. C 2015, 56, 165. [CrossRef] [PubMed]

30. Fantini, M.; Curto, M.; Crescenzio, F.D. A method to design biomimetic scaffolds for bone tissue engineering based on voronoi lattices. Virtual Phys. Prototyp. 2016, 1-14. [CrossRef]

31. Deplaine, H.; Acosta-Santamaría, V.A.; Vidaurre, A.; Gómez Ribelles, J.L.; Doblaré, M.; Ochoa, I.; Gallego Ferrer, G. Evolution of the properties of a poly(L-lactic acid) scaffold with double porosity during in vitro degradation in a phosphate-buffered saline solution. J. Appl. Polym. Sci. 2014, 131, 1366-1373. [CrossRef]

32. Fu, Q.; Saiz, E.; Rahaman, M.N.; Tomsia, A.P. Tissue engineering: Toward strong and tough glass and ceramic scaffolds for bone repair. Adv. Funct. Mater. 2013, 23, 5461-5476. [CrossRef]

33. Chauhan, S.R.; Thakur, S. Effects of particle size, particle loading and sliding distance on the friction and wear properties of cenosphere particulate filled vinylester composites. Mater. Des. 2013, 51, 398-408. [CrossRef]

34. Bahari, S.A.; Krause, A. Utilizing malaysian bamboo for use in thermoplastic composites. J. Clean. Prod. 2015, 110, 16-24. [CrossRef]

35. Kumar, P.; Singh, P.; Pandey, K.N.; Verma, V.; Kumar, V. Poly(ether ether)ketone/poly(ether) imide nanocomposites. Asian J. Res. Chem. 2012, 5, 703-706.

36. Wang, Y.C.; Lin, M.C.; Wang, D.M.; Hsieh, H.J. Fabrication of a novel porous pga-chitosan hybrid matrix for tissue engineering. Biomaterials 2003, 24, 1047-1057. [CrossRef]

37. Handel, M.; Hammer, T.R.; Nooeaid, P.; Boccaccini, A.R.; Hoefer, D. 45s5-bioglass $\left({ }^{\circledR}\right)$-based 3D-scaffolds seeded with human adipose tissue-derived stem cells induce in vivo vascularization in the cam angiogenesis assay. Tissue Eng. Part A 2013, 19, 2703-2712. [CrossRef] [PubMed]

38. Tsutsumi, Y.; Nishimura, D.; Doi, H.; Nomura, N.; Hanawa, T. Cathodic alkaline treatment of zirconium to give the ability to form calcium phosphate. Acta Biomater. 2010, 6, 4161-4166. [CrossRef] [PubMed]

39. Cohen, D.; Shoham, O.; Orr, N.; Muhsen, K. An inverse and independent association between helicobacter pylori infection and the incidence of shigellosis and other diarrheal diseases. Clin. Infect. Dis. 2012, 54, 35-42. [CrossRef] [PubMed]

40. Rui, M.; Li, Q.; Lin, W.; Zhang, X.; Lin, F.; Luo, Z.; Bai, X.; Lei, M. Mechanical properties and in vivo study of modified-hydroxyapatite/polyetheretherketone biocomposites. Mat. Sci. Eng. C 2017, 73, 429-439.

41. Wong, H.M.; Chu, P.K.; Leung, F.K.; Cheung, K.M.; Luk, K.D.; Yeung, K.W. Engineered polycaprolactone-magnesium hybrid biodegradable porous scaffold for bone tissue engineering. Prog. Nat. Sci. 2014, 24, 561-567. [CrossRef]

42. Yang, Y.; Wu, P.; Lin, X.; Liu, Y.; Bian, H.; Zhou, Y.; Gao, C.; Shuai, C. System development, formability quality and microstructure evolution of selective laser-melted magnesium. Virtual Phys. Prototyp. 2016, 11, 173-181. [CrossRef]

43. Gao, C.; Liu, T.; Shuai, C.; Peng, S. Enhancement mechanisms of graphene in nano-58s bioactive glass scaffold: Mechanical and biological performance. Sci. Rep. 2014, 4, 4712. [CrossRef] [PubMed]

44. Bellucci, D.; Bolelli, G.; Cannillo, V.; Cattini, A.; Sola, A. In situ raman spectroscopy investigation of bioactive glass reactivity: Simulated body fluid solution vs tris-buffered solution. Mater. Charact. 2011, 62, 1021-1028. [CrossRef]

45. Sun, H.; He, S.; Wu, P.; Gao, C.; Feng, P.; Xiao, T.; Deng, Y.; Shuai, C. A novel mgo-cao-sio2 system for fabricating bone scaffolds with improved overall performance. Materials 2016, 9, 287. [CrossRef]

46. Sánchez-Salcedo, S.; Colilla, M.; Izquierdo-Barba, I.; Vallet-Regí, M. Preventing bacterial adhesion on scaffolds for bone tissue engineering. Int. J. Bioprint. 2016, 2, 20-23. [CrossRef]

Sample Availability: Samples of the PEEK/PGA-KDIOP are available from the authors. 